\title{
Impact of two root systems, earthworms and mycorrhizae on the physical properties of an unstable silt loam Luvisol and plant production
}

\author{
Roxane Kohler-Milleret • Renée-Claire Le Bayon • \\ Claire Chenu • Jean-Michel Gobat • Pascal Boivin
}

Received: 29 June 2012 / Accepted: 30 January 2013 / Published online: 13 February 2013

(C) Springer Science+Business Media Dordrecht 2013

\begin{abstract}
Background and aims Soil organisms are known to engineer the soil physical properties, but their impact is difficult to assess and poorly documented. Shrinkage analysis has a good potential for such assessment. This study analyses the effects of mycorrhizae (Glomus intraradices), earthworms (Allolobophora chlorotica) and two plants, Allium porrum (leek) and Petunia hybrida (petunia), on the physical properties of an unstable loamy Luvisol, as well as the biological interactions between the soil organisms.

Methods In addition to soil organism biomass, shrinkage analysis and soil aggregate stability analysis were used to characterize the soil physical properties.
\end{abstract}

Responsible Editor: Nico Eisenhauer.

R. Kohler-Milleret $(\bowtie) \cdot$ R.-C. Le Bayon · J.-M. Gobat Laboratory Soil and Vegetation, Institute of Biology, University of Neuchâtel,

Emile-Argand 11, CP 158,

2009 Neuchâtel, Switzerland

e-mail: Roxane.Kohler@unine.ch

C. Chenu

UMR 7618 CNRS Bioemco, Bâtiment EGER,

AgroParisTech,

78850 Thiverval Grignon, France

P. Boivin

Soils and Substrates, University of Applied Sciences

of Western Switzerland (HES-SO), hepia,

150 , route de Pressinge,

1254 Jussy, Geneva, Switzerland
Results The soil aggregate stability, specific volume and structural pores volumes were increased with plant roots compared to control. The drilling effect of roots could not explain the pore volume increase, which was several orders of magnitude larger than the volume of the roots. Leek had larger impact on volumes while petunia mostly increased soil aggregate stability. Mycorrhizae increased the soil stability and the soil volume. Earthworms alone decreased the pore volumes at any pore size, and plant roots mitigated this.

Conclusions Our results highlight (1) the large impact of soil biota on soil physical properties, (2) that their separated effects can either combine or mitigate each other and (3) that the observed changes are varying in intensity according to soil type and plant type.

Keywords Shrinkage analysis · Soil porosity - Earthworms · Arbuscular mycorrhizal fungi $($ AMF $) \cdot$ Root network $\cdot$ Soil structure

\section{Introduction}

Soil organisms are known to play a crucial role in soil ecological processes such as organic matter turnover, nutrient cycling and engineering of the soil physical properties. They are, therefore, essential to soil fertility and nutrient uptake by plants (Bradford et al. 2002; Wardle et al. 2004). The soil physical habitat is widely assumed to be of prime importance in determining and regulating biological activities (Young and Crawford 
2004). As a result, interactions between soil physics and the biological and chemical processes are key determinants of ecosystem health (Feeney et al. 2006), but are still largely to be deciphered.

Plant roots, microorganisms (bacteria and fungal mycelium) and soil fauna such as earthworms or termites are considered to be major engineers for soil aggregation and porosity (Amezketa 1999; Jastrow and Miller 1991; Six et al. 2004; Tisdall and Oades 1982). As reviewed in Angers and Caron (1998), roots affect soil structure through direct and indirect mechanisms such as root penetration creating porosity and favouring water transport, or soil enmeshment and root exudation increasing soil aggregation and stability or enhancing microbial activity, which in turn will affect soil structure. Arbuscular mycorrhizal fungi (AMF) are also known to influence soil physical processes with soil particles entanglement and gluesubstance secretion such as glomalin, but the respective effects of roots and AMF are still a matter of debate due to the symbiotic relationship between plants and AMF (Hallett et al. 2009; Jastrow et al. 1998; Thomas et al. 1993). Through burrowing, casting and mixing of litter and soil (bioturbation), earthworms modify the structure, stability, water infiltration and aeration of soils (Edwards and Bohlen 1996). Furthermore, plant roots, AMF and earthworms interact in the soil. Recent studies showed that individual effects of soil organism groups may mitigate the impact of each other when combined (Bradford et al. 2002; Wurst et al. 2008). Assessing the impact of soil biota on soil physical properties needs to address many properties (e.g. soil density, soil structural stability, pore and aggregate size distribution and hydraulic conductivity), thus requiring many experiments. Precise and accurate measurements are required, which is especially difficult when considering the very heterogeneous soil media and the large variability of the soil physical properties. Shrinkage analysis, however, has the potential to overcome this difficulty since it allows determining together most of these properties in a single experiment with small standard errors (Boivin 2007).

By using shrinkage analysis, Milleret et al. (2009b) assessed for the first time the impact of soil biota on soil physical properties. This experiment was performed in microcosms on a carbonated loamy Anthrosol with a well-developed and stable structure, which was cropped with leeks. While performed on a limited number of samples, the results of the shrinkage analysis showed that, at any water content, endogeic earthworms decreased the specific bulk volume and hydro-structural stability and increased the bulk soil density. On the contrary, leek roots decreased the bulk soil density and increased the hydro-structural stability. The increase in soil volume was attributed to the development of structural pores, volume of which was about three orders of magnitude larger than root volume, and size of which was either larger and smaller than the roots, thus suggesting an indirect effect of roots on soil structure rather than a direct root drilling effect. Moreover, a positive synergistic effect between AMF and roots in the absence of earthworms was highlighted.

The effects of soil organisms on soil structure may vary with different soil type and root system. Weakly structured soils may interact differently with soil biota than the Anthrosol, and limitations in applying shrinkage analysis can be expected with such soils. The aim of this paper is to test these expectations. Therefore, we performed a microcosm experiment by using a silt loam Luvisol and different plant species. Silt loam Luvisol are characterized by a small structural stability (Cosentino et al. 2006), and are encountered on large cropped areas, contrarily to the previously experimented Anthrosol. Shrinkage analysis was developed for dual porosity soils and seldom applied to silt soils. In addition to the impact of soil organisms such as AMF (Glomus intraradices, Schenk \& Smith) and endogeic earthworms (Allolobophora chlorotica, Savigny), we introduced two different model plants, namely the leek (Allium porrum L.) and the petunia (Petunia hybrida, Jussieu), to compare the effect of monocotyledon and dicotyledon root systems on soil physical properties. The leek (monocotyledon) was used in the previous experiment (Milleret et al. 2009b), while the petunia belongs to the widely cropped Solanaceae family and was formerly selected by the NCCR "Plant Survival" project to which this research belongs. The biological interactions between the soil organisms are first described, and their effects on soil properties are then discussed based on soil aggregate stability measurements and shrinkage analysis.

\section{Material and methods}

Experimental setup, plant, mycorrhiza and earthworm

The silt loam Luvisol was sampled at the experimental site of the Institut National de la Recherche 
Agronomique-INRA- $\left(48^{\circ} 48^{\prime} 29^{\prime \prime} \mathrm{N}, 2^{\circ} 04^{\prime} 58^{\prime \prime} \mathrm{E}\right)$, at Versailles City, France (Cosentino et al. 2006). The texture was $167 \mathrm{~g} \mathrm{~kg}^{-1}$ clay, $562 \mathrm{gkg}^{-1}$ silt and $271 \mathrm{~g} \mathrm{~kg}^{-1}$ sand, with a total carbon content of $9.0 \mathrm{~g} \mathrm{~kg}^{-1}, \mathrm{C}_{\mathrm{t}} / \mathrm{N}_{\mathrm{t}}: 9.3, \mathrm{pH}\left(\mathrm{H}_{2} \mathrm{O}\right)$ of 7.0. It had been cultivated for more than 50 years with conventional tillage (mouldboard plow at $0-30 \mathrm{~cm}$ ) with a rotation based on wheat (Triticum aestivum L.), colza (Brassica napus L.) and pea (Pisum sativum L.).

The soil was carefully collected at $0-25 \mathrm{~cm}$ depth ( $A_{\mathrm{p}}$ horizon) with shovels to keep the natural structure of the soil as much as possible.

The soil was air-dried, sieved to $2 \mathrm{~mm}$ size aggregates, homogenized and sterilized by autoclaving $(1 \mathrm{~h}$ at $121^{\circ} \mathrm{C}$ for two consecutive days). Soil sterility was checked by spreading soil dilutions on Angle (Angle et al. 1991) and Malt Agar media, and no microorganisms were detected. The soils were repacked in the microcosms (PVC tube; $35 \mathrm{~cm}$ height and $15 \mathrm{~cm}$ internal diameter) with a bulk density of $1.18 \mathrm{~g} \mathrm{~cm}^{-3}$ using the procedure of Boivin et al. (2004). Afterwards, a $65-\mathrm{ml}$ soil suspension $(100 \mathrm{~g}$ of soil dispersed in 11 of autoclaved distilled $\mathrm{H}_{2} \mathrm{O}$ and filtered on $11-\mu \mathrm{m}$ paper) was added to re-inoculate the sterilized soil with microorganisms but without AMF (Koide and Li 1989).

Applied treatments were the possible combinations of the three following factors: (1) the three treatments of plant species, i.e. unplanted, three leek plantlets (A. porrum var. Mercure) or three petunia plantlets (P. hybrida $\mathrm{W} 115)$ germinated in sterile conditions, (2) the presence/absence of AMF [G. intraradices; $20 \mathrm{ml}$ per microcosm of inoculum suspension ( $100 \mathrm{~g}$ of culture sand substrate mixed with $G$. intraradices spores and hyphae dispersed in 11 of autoclaved distilled $\mathrm{H}_{2} \mathrm{O}$, the AMF-free treatments were in addition filtered on $11-\mu \mathrm{m}$ paper)] and (3) the presence/absence of endogeic earthworms [A. chlorotica; nine individuals of equal biomass ( $0.73 \mathrm{~g}$ fresh biomass per kilogram of soil)]. The choice of the endogeic species is based on the surprising results of Chauvel et al. (1999) and Milleret et al. (2009b) showing that tropical and temperate endogeic earthworms, respectively, were susceptible to heavily compact the topsoil and because this species was present in the sampled soil (Pelosi et al. 2009).

Treatments containing AMF without plants are not possible due to the obligate symbiosis between plant roots and AMF. Consequently, according to the presence or absence of earthworm (E), leek (L), petunia
(P) and $\mathrm{AMF}(\mathrm{A})$, a total of ten treatments were applied $(\mathrm{C}, \mathrm{E}, \mathrm{L}, \mathrm{P}, \mathrm{L}+\mathrm{E}, \mathrm{P}+\mathrm{E}, \mathrm{L}+\mathrm{A}, \mathrm{P}+\mathrm{A}, \mathrm{L}+\mathrm{E}+\mathrm{A}$ and $\mathrm{P}+\mathrm{E}+\mathrm{A})$. The control $\mathrm{C}$ corresponds to the treatment without plant, earthworm and AMF. All treatments were replicated three times resulting in a total of 30 microcosms.

The microcosms were kept 22 weeks in an experimental greenhouse under the following conditions: photoperiod $16 / 8 \mathrm{~h}$ (day/night), temperature $16 \pm 2{ }^{\circ} \mathrm{C}$ and $50 \%$ air moisture content. Irrigation was performed twice a week using a modified Hoagland's nutrient solution without $\mathrm{P}$ in order to promote the AMF-plant symbiosis. Every 3 weeks, each microcosm was weighted and adjusted to equal soil water content with deionised water.

\section{Sampling of microcosms}

After 22 weeks, shoots were cut at ground level, pooled, air-dried and weighed. Four undisturbed soil cores of approximately $100 \mathrm{~cm}^{3}$ were removed from the middle of the microcosms for soil shrinkage curve (ShC), water retention curve (WRC) and root size distribution measurements. The remaining soil was thoroughly mixed, and roots were sampled in a fraction of $500 \mathrm{~g}$ of soil. The roots were, therefore, carefully washed, air-dried and weighed. Earthworms were hand-collected, counted and weighed.

\section{Mycorrhiza analysis}

To measure AMF root infection, roots were first cleared in $10 \% \mathrm{KOH}$, acidified in $1 \% \mathrm{HCl}$ and stained in $0.05 \%$ Trypan blue in lactoglycerol. The percentage of AMF colonisation was determined on 150 root segments at $\times 250$ magnification using a modified line intersect method (McGonigle et al. 1990).

\section{Root size distribution}

Specific root volume in the soil cores used for shrinkage analysis (see below) was measured as previously described in Milleret et al. (2009b). Briefly, roots were scanned at high resolution. The dry length, diameter, surface and volume area of the scanned fragments were calculated using an image analysis program (Image J v.1.40, National Institute of Health, USA).

In order to convert the dried root volume (DV) to the fresh volume (FV), we previously applied the same 
procedure on fresh leek and petunia root segments that were thereafter dried overnight. This allowed determining the two following regressions:

$\mathrm{FV}=1.551 \mathrm{DV}+0.001$

and

$\mathrm{FV}=1.191 \mathrm{DV}-0.0006$

for the leek $\left(r^{2}=0.79, P<0.001, n=76\right)$ and petunia $\left(r^{2}=\right.$ $0.99, P<0.001, n=30)$, respectively.

The specific root volumes (total and $<250 \mu \mathrm{m}$ diameter) and the total root length were finally divided by the soil core weight in order to have the total specific fresh root volume $\left(\mathrm{SRV}_{\mathrm{t}}\right)$, the specific $<250 \mu \mathrm{m}$ diameter fresh root volume $\left(\mathrm{SRV}_{<250}\right)$ and the specific root length (SRL) per gram of soil.

\section{Soil analysis}

\section{Macroaggregate water stability}

The water-stable soil macroaggregates in the 1-2-mm size class ( $\mathrm{WSA}_{1-2} \mathrm{~mm}$ ) were determined using the wet-sieving apparatus (Kemper and Rosenau 1986). A $250-\mu \mathrm{m}$ sieve was filled with a 4 -g sample of 1$2 \mathrm{~mm}$ air-dried aggregates. The samples were then moistened by capillarity with deionised water for $10 \mathrm{~min}$ and wet-sieved $10 \mathrm{~min}$ more with a stroke length of $19 \mathrm{~min}^{-1}$. The WSA corresponded to the amount of macroaggregates $(>250 \mu \mathrm{m})$ remaining on the sieve and was expressed as a percentage of the total initial mass of soil after correction for the weight of coarse particles $(>0.25 \mathrm{~mm})$.

\section{Shrinkage analysis}

The soil shrinkage curve (ShC) was defined as the soil volume change with water content (Haines 1923). It can be measured on undisturbed soil samples together with the water retention curve (WRC) using the experimental setup described in Boivin et al. (2004). Shrinkage analysis consists in determining the changes in volume, air and water content of the two soil pore systems, namely plasma and structural pores, and the hydro-structural stability of the soil, by modelling the ShC with XP model (Braudeau et al. 1999). The structural pores are the cracks, biopores and packing voids (Brewer 1964), accounting for rapid air and water transfers in the soil. The structural pore volume is mostly due to pores with radii larger than $10 \mu \mathrm{m}$ (Boivin et al. 2004). The plasma is made of the soil colloids (Brewer 1964 and SSSA Glossary). The plasma pores are mostly smaller than $10 \mu$ m radius; they remain saturated on most of the soil water content range (see e.g. Tessier 1980) and act as a buffer for water and nutrient. The plasma is sometimes referred to as clay matrix, textural porosity, or organo-mineral complex, but these wordings are less comprehensive than plasma. The two pore systems behave differently with changes in soil water content and in front of external stresses; therefore, quantifying them allows improving the diagnosis of soil physical properties and soil compaction in particular (Schaeffer et al. 2008; Boivin et al. 2006).

Quasi-continuous ShC and water retention curves (WRC) were determined simultaneously on the undisturbed soil cores with the same devices as presented in Boivin et al. (2004) and Milleret et al. (2009b). We wetted the soil samples by applying a matrix potential of $-10 \mathrm{hPa}$ with respect to the centre of the samples. This means that pore radii up to $150 \mu \mathrm{m}$ were filled with water.

During drying, the samples were placed on electronic balances $(0.01 \mathrm{~g}$ precision) contained in a thermostatic chamber at $20^{\circ} \mathrm{C}$. Calibrated displacement transducers (resolution of $1 \mu \mathrm{m}$ ) were used to measure changes in sample height during drying. Tensiometers (ceramic cups; length $2.0 \mathrm{~cm}$, diameter $0.2 \mathrm{~cm}$ ) connected to pressure transducers were inserted at the centre of the samples to record the matrix potential. Weight, height and water potential were recorded at intervals of 5 min until the sample weights reached constant values, which took about 4 days. Then, the dry sample volumes were determined by means of hydrostatic weighing with the plastic bag method described by Boivin et al. (1990), and the samples were dried in an oven at $105^{\circ} \mathrm{C}$ for $24 \mathrm{~h}$ to obtain the dry weight.

Changes in sample height were converted to changes in specific bulk sample volume by

$V=V_{E} \times\left(\frac{H}{H_{E}}\right)^{3}$,

where the exponent 3 denotes isotropic shrinkage (e.g. Boivin 2007), $V_{\mathrm{E}}$ and $H_{\mathrm{E}}$ are the specific bulk volume and height at the end of the experiment, and $V$ and $H$ are the bulk volume and height during the experiment.

The XP model equations (Braudeau et al. 1999) were subsequently fitted to the experimental shrinkage 
data by a non-linear simplex method (Chen and Saleem 1986) to determine the coordinates of the transition points between the shrinkage domains (Fig. 1), namely shrinkage limit (SL), air entry (AE), the dry point of structural porosity (ML) and the maximum swelling of the plasma (MS).

Using the XP model equations for the plasma porosity (Braudeau and Bruand 1993), we then calculated the specific plasma porosities, $V_{\mathrm{p}}$ (in cubic centimetres per gram of soil), and the plasma water content, $W_{\mathrm{p}}$ (in grams per gram of soil). The specific air content of the plasma, $A_{\mathrm{p}}$, was calculated as

$A_{\mathrm{p}}=V_{\mathrm{p}}-W_{\mathrm{p}}$.

The specific structural porosity, $V_{\mathrm{s}}$, was calculated as

$V_{\mathrm{s}}=V-V_{\mathrm{p}}-\rho^{-1}$,

where $\rho^{-1}$ is the specific volume of the solid phase (set to $1 / 2.65 \mathrm{~cm}^{3} \mathrm{~g}^{-1}$ ). At SL and AE, this volume corresponds to the specific air content of the structural porosity $\left(A_{\mathrm{s}}\right)$. Moreover, we calculated the air-filled porosity at $-10 \mathrm{hPa} A_{\text {sat }}$ (in cubic centimetre per gram of soil) as

$A_{\text {sat }}=V-W_{\text {sat }}-\rho^{-1}$,

where $W_{\text {sat }}$ (in grams per gram of soil) is the sample gravimetric water content at $-10 \mathrm{hPa}$. Bulk density was calculated as the inverse of the specific bulk volume.

The simultaneous weight and tensiometer measurements were used to determine the water retention curves (WRC). We converted these curves into the pore-size distributions of equivalent cylindrical pores using the Jurin-Laplace equation (e.g. Lawrence 1977).

After ShC and WRC analysis, the undisturbed samples were broken up to measure the root length and volume in each soil sample (see the "Root size distribution" section).

\section{Statistical analysis}

We performed the statistical analyses with R 2.6.0 (R Development Core Team 2007). Normal distribution and homogeneity of variance were improved by logtransformation, if necessary, but non-transformed means are represented in text and figures $( \pm \mathrm{SE})$. Analysis of variance (ANOVA) was used to analyze the effects of earthworms (factor with two levels: the presence or absence of $A$. chlorotica) and plant species (factors with two levels: leek or petunia) on root mycorrhization. ANOVA was also used to analyze the effects of AMF (factor with two levels: the presence or absence of $G$. intraradices) and plant species (factors with three levels: unplanted, leek or petunia) on earthworm survival and body fresh weight. In addition, ANOVA was used to analyze the effects of earthworms, AMF and plant species (factors with two levels: leek or petunia) on plant productivity (shoot, root and total biomass and shoot-to-root ratio per microcosm) and root size distribution parameters. For the soil analyses, ANOVA was performed to analyze the effects of earthworms, AMF and plant species (factors with three levels: unplanted, leek or petunia) on the percentage of water-stable macroaggregates. A PCA was performed on the different quantitative shrinkage parameters. The dimdesk function (available in FactoMineR, an $\mathrm{R}$ package for multivariate analysis) was thereafter applied in order to test the significance of each correlation coefficient between the variable and the coordinates of the individuals on the axis (Le et al. 2008). This enables us to highlight the variables that significantly describe each dimension (axis) of the PCA. Three-ways ANOVAs were thereafter performed on the coordinates of the two first axes in order to test the effects of the soil organisms.

\section{Results}

\section{Biological interactions}

The percentage of plant root colonization in treatments without AMF (control) was negligible $(2.9 \pm 1.2 \%)$. After 22 weeks, the mean root colonization of the AMF treatments was $20.1 \pm 3.4 \%$. Total mycorrhization of plant roots in the AMF treatment was not significantly different between the two plant species $\left(F_{1,8}=1.75, P=0.22\right)$ nor between the presence or absence of earthworms $\left(F_{1,8}=1.21, P=0.30\right)$.

At the end of the experiment, visual observations of the soil column after removal of the microcosm indicated that the soil was entirely affected by earthworms and that the burrows reached the bottom of the column. Despite this apparent good activity, only 11 individuals of the initial 75 were collected after the 22-week experiment (14.7\%), which represents only 
$12.4 \pm 3.9 \%$ of the initial body fresh weight. However, survival of $A$. chlorotica was neither affected by plant species $\left(F_{2,10}=0.04 P=0.96\right)$ nor by the presence of $\operatorname{AMF}\left(F_{1,10}=0.07, P=0.80\right)$. Similarly, the body fresh weight of earthworms was not affected by plant species $\left(F_{2,10}=0.27, P=0.77\right)$ nor by the presence of $\operatorname{AMF}\left(F_{1,10}=0.07, P=0.80\right)$.

Total biomass of $P$. hybrida per microcosm (106.5 \pm $6.0 \mathrm{~g})$ was greater than $A$. porrum $(22.7 \pm 2.5 \mathrm{~g}$; Table 1). Shoot biomass of $P$. hybrida exceeded that of $A$. porrum, but root biomass did not differ significantly between both plant species (Table 1 and Fig. 2). The presence of AMF increased dried roots $(\times 3.2)$ and shoots $(\times 1.3)$ of $P$. hybrida as well as dried roots $(\times 2.0)$ and shoots $(\times 1.4)$ of A. porrum (Fig. 2). The shoot-to-root ratio was significantly different between plant species and significantly affected by the presence of AMF (Table 1). Finally, earthworms did not affect plant biomass in the present experiment, and no interaction between earthworms and AMF was measured.

Total specific root volume $\left(\mathrm{SRV}_{\mathrm{t}}\right)$, specific root volume $<250 \mu \mathrm{m}\left(\mathrm{SRV}_{<250}\right)$ and total specific root length (SRL) measured in the soil cores used for shrinkage analyses are presented in Table 2 . Earthworm significantly decreased $\mathrm{SRV}_{\mathrm{t}}$ and $\mathrm{SRV}_{<250}$, but the presence of AMF significantly increased the SRL of both species. Total SRV was not different between plant species, while the $\mathrm{SRV}_{<250}$ was larger in the presence of petunia. Moreover, the SRL of petunia was much larger than leek, thus indicating that petunia roots architecture is more branched than leek roots and have a lower mean root diameter.
Soil analysis

\section{Macroaggregate water stability}

Overall, the percentage of water-stable macroaggregates in the 1-2-mm size class (WSA $1-2 \mathrm{~mm}$ ) was small, ranging between $1.9 \%$ and $9.4 \%$. The percentage of $\mathrm{WSA}_{1-2} \mathrm{~mm}$ was 1.4 times larger in the presence of $\operatorname{AMF}\left(F_{1,20}=14.620, P=0.001\right.$; Fig. 3$)$. In addition, this percentage was significantly affected by the plant species $\left(F_{2,20}=10.31, P<0.001\right)$ in the following manner: petunia $>$ leek $>$ unplanted. In the presence of $P$. hybrida, the macroaggregates were two times more stable and 1.6 times with $A$. porrum than within the unplanted microcosms. The percentage of $\mathrm{WSA}_{1-2} \mathrm{~mm}$ was not affected by the presence of earthworm in the microcosms.

\section{Experimental shrinkage curves}

Throughout shrinkage analysis, we observed several shapes of ShC (Fig. 4). In Fig. 4a, we observed a classical S-shape curve such as described by Braudeau et al. (1999), thus presenting the four shrinkage domains described by XP model. In parallel, we also observed S-shape curves with the additional interpedal phase as described by Braudeau et al. (2004) (Fig. 4b) and doubled S-shape curves (Fig. 4c) that have not been reported so far. XP model is determined by fitting the four transition points SL, AE, ML and MS presented in Fig. 1. While these points are easy to fit in the two first cases, the coordinates of ML and MS cannot be unambiguously fitted in the third case (Fig. 4c). Further theoretical development is required
Fig. 1 Example of a shrinkage curve with the transition points ( $S L$ shrinkage limit, $A E$ air entry, $M L$ macroporosity limit, $M S$ maximum swelling); the cumulated calculated specific volumes (solid phase, black dotted line; saturation 1:1 line separating water and air volumes, long dotted line; dotted line; plasma and structural porosity, grey solid line; and bulk soil, bold black solid line)

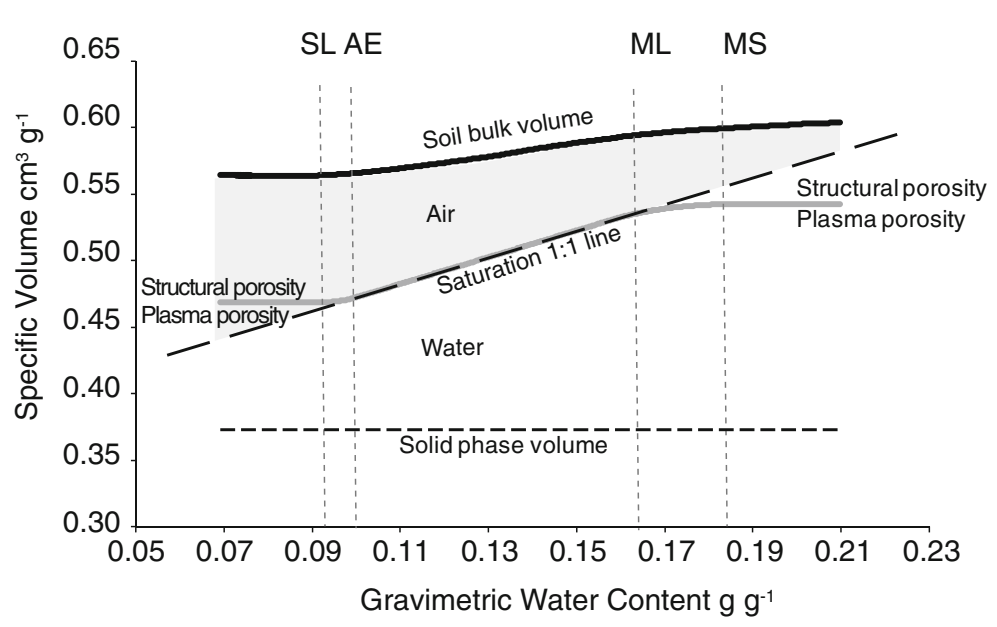


Table 1 ANOVA table showing the effects of plant species (leek and petunia), earthworms and AMF on total biomass (grams), dried roots (grams), shoot (grams) and shoot-to-root ratio

\begin{tabular}{|c|c|c|c|c|c|c|c|c|c|c|c|c|c|}
\hline & \multirow{2}{*}{$d f$} & \multicolumn{3}{|c|}{ Total biomass } & \multicolumn{3}{|c|}{ Root biomass } & \multicolumn{3}{|c|}{ Shoot biomass } & \multicolumn{3}{|c|}{ Shoot-to-root ratio } \\
\hline & & $F$ & $P$ & & $F$ & $P$ & & $F$ & $P$ & & $\mathrm{~F}$ & $P$ & \\
\hline Plant species & 1 & 291.01 & $* * * *$ & $\mathrm{P}>\mathrm{L}$ & 4.40 & * & & 532.75 & $* * * *$ & $\mathrm{P}>\mathrm{L}$ & 151.64 & $* * * *$ & $\mathrm{P}>\mathrm{L}$ \\
\hline Earthworm & 1 & 0.84 & & & 0.41 & & & 1.01 & & & 0.17 & & \\
\hline $\mathrm{AMF}$ & 1 & 12.73 & $* * *$ & $\uparrow$ & 13.29 & $* * *$ & $\uparrow$ & 12.01 & $* * *$ & $\uparrow$ & 8.26 & $* *$ & $\downarrow$ \\
\hline Plant species $\times$ earthworm & 1 & 0.78 & & & 0.19 & & & 1.11 & & & 0.01 & & \\
\hline Plant species $\times$ AMF & 1 & 0.62 & & & 0.28 & & & 0.32 & & & 1.79 & & \\
\hline Earthworm $\times$ AMF & 1 & 0.34 & & & 0.06 & & & 0.04 & & & 0.002 & & \\
\hline Plant species $\times$ earthworm $\times$ AMF & 1 & 1.83 & & & 3.51 & $*$ & & 0.93 & & & 3.07 & $*$ & \\
\hline Residuals (MS) & 16 & 0.05 & & & 0.20 & & & 0.04 & & & 0.17 & & \\
\hline
\end{tabular}

$d f$ degrees of freedom, $M S$ mean square

$\uparrow=$ increase; $\downarrow=$ decrease, $\mathrm{P}>\mathrm{L}=$ petunia greater than leek

$* P<0.1 ; * * P<0.05 ; * * * P<0.01 ; * * * * P<0.001$

to better understand these curves, which is not the aim of the present study. In the following, assuming that the air entry and shrinkage limit are determined at the dry end of the $\mathrm{ShC}$ we, therefore, focused our analyses

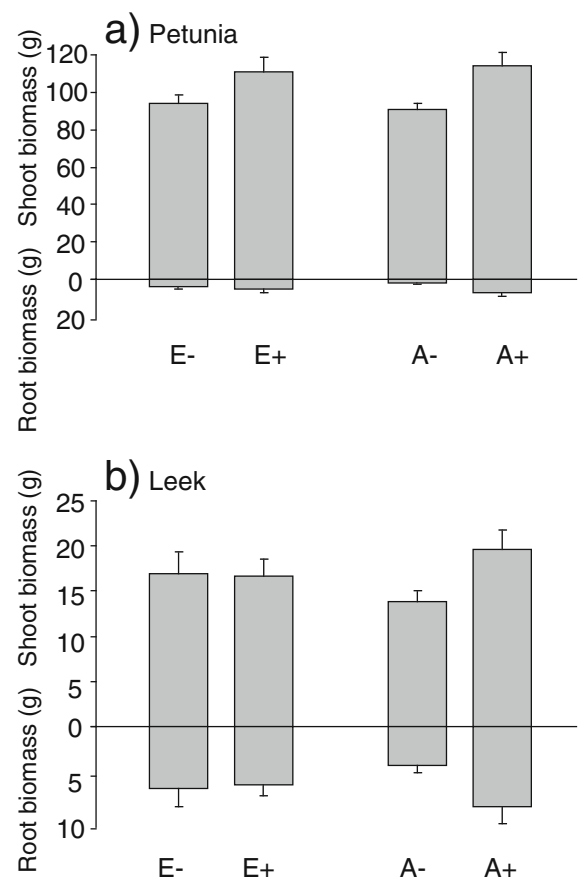

Fig. 2 Variation in shoot and root biomass (grams dry weight per microcosm) of (a) petunia (Petunia hybrida) and (b) leek (Allium porrum) as affected by the presence of earthworms $(E$, Allolobophora chlorotica) and AMF (A, Glomus intraradices). Bar represents mean $+\mathrm{SE}$ on the specific plasma porosity, water and air content at $\mathrm{SL}$ and $\mathrm{AE}$ and on the specific structural porosity at $\mathrm{SL}, \mathrm{AE}$ and air content at saturation (i.e. $-10 \mathrm{hPa}$ ) whose determination are independent from the MS and ML coordinates.

\section{Shrinkage curves and pore-size distribution}

Figure 5 shows the ShCs of the whole dataset. Figure 5a shows that earthworm treatment curves (E) resulted in smaller specific volume than the control (C), meaning a compaction (larger soil density) in the presence of earthworm without plants. Overall, the specific volume of every sample was comprised between 0.7 and $0.9 \mathrm{~cm}^{3} \mathrm{~g}^{-1}$, except for two samples (see Fig. 5b, d). In the presence of plants [continuous (leek) and dotted (petunia) black lines on Fig. 5b-e], we observed that ShCs of similar treatments were largely spread on the volume axis, leek samples showing a larger variation among a treatment compared with petunia samples. In comparison with petunia samples, the specific volume of leek samples was generally larger. This was particularly clear when AMF was added to the treatment (Fig. 5d). In this case, L+A samples presented larger specific volume than the unplanted control, and the $\mathrm{P}+\mathrm{A}$ samples stood at a similar specific volume than the unplanted control. When earthworms and AMF treatments are combined, the bulk volumes did not seem to be increased by roots (Fig. 5e). 
Table 2 Mean values $( \pm \mathrm{SE})$ of the total specific root volume (SRV, cubic centimetre per gram of soil), the specific root volume of root diameter $<250 \mu \mathrm{m}$ (SRV $<250 \mu \mathrm{m}$, cubic centimetre per gram of soil) and total specific root length (SRL, centimetre per gram of soil) measured in the soil

\begin{tabular}{|c|c|c|c|c|}
\hline Treatment & $d f$ & Total SRV & $\mathrm{SRV}<250 \mu \mathrm{m}$ & Total SRL \\
\hline $\mathrm{L}$ & & $1.05 \mathrm{E}-03(3.55 \mathrm{E}-04)$ & 4.76E-04 (2.37E-04) & $1.45(0.63)$ \\
\hline $\mathrm{L}+\mathrm{E}$ & & $9.75 \mathrm{E}-04(3.07 \mathrm{E}-04)$ & 2.82E-04 (1.45E-04) & $1.05(0.29)$ \\
\hline $\mathrm{L}+\mathrm{A}$ & & $1.25 \mathrm{E}-03(1.43 \mathrm{E}-04)$ & 7.64E-04 (4.34E-05) & $2.35(0.35)$ \\
\hline $\mathrm{L}+\mathrm{A}+\mathrm{E}$ & & $5.15 \mathrm{E}-04(9.03 \mathrm{E}-05)$ & $3.30 \mathrm{E}-04(4.38 \mathrm{E}-05)$ & $1.08(0.11)$ \\
\hline $\mathrm{P}$ & & $1.41 \mathrm{E}-03(0.00)^{\mathrm{a}}$ & $1.18 \mathrm{E}-03(0.00)^{\mathrm{a}}$ & $3.25(0.00)^{\mathrm{a}}$ \\
\hline $\mathrm{P}+\mathrm{E}$ & & $6.62 \mathrm{E}-04(5.83 \mathrm{E}-05)$ & 5.13E-04 (5.94E-05) & $3.34(0.21)$ \\
\hline $\mathrm{P}+\mathrm{A}$ & & $1.44 \mathrm{E}-03(2.91 \mathrm{E}-05)$ & $1.06 \mathrm{E}-03(1.13 \mathrm{E}-04)$ & $5.08(1.32)$ \\
\hline $\mathrm{P}+\mathrm{A}+\mathrm{E}$ & & $9.90 \mathrm{E}-04$ (5.95E-05) & 7.88E-04 (1.33E-04) & $4.92(0.68)$ \\
\hline \multicolumn{5}{|l|}{ ANOVA $F$ value } \\
\hline Plant species & 1,13 & 0.29 & $11.66^{* *}$ & $42.79 * * *$ \\
\hline Earthworm & 1,13 & $9.86 * *$ & $13.50 * *$ & 2.20 \\
\hline $\mathrm{AMF}$ & 1,13 & 0.05 & 2.83 & $5.00 *$ \\
\hline Plant species $\times$ earthworm & 1,13 & 0.40 & 0.28 & 0.55 \\
\hline Plant species $\times$ AMF & 1,13 & 1.41 & 0.01 & 1.93 \\
\hline Earthworm $\times$ AMF & 1,13 & 0.90 & $<0.01$ & 0.54 \\
\hline $\begin{array}{l}\text { Plant species } \times \\
\text { earthworm } \times \text { AMF }\end{array}$ & 1,13 & 2.23 & 2.35 & 0.12 \\
\hline
\end{tabular}

$L$ leek, $P$ petunia, $E$ earthworms, $A$ AMF, $d f$ degrees of freedom

$* P<0.05 ; * * P<0.01 ; * * * P<0.001$

${ }^{\text {a }}$ No replicate available

The shrinkage properties derived from the XP model parameters at $\mathrm{SL}, \mathrm{AE}$ and at $-10 \mathrm{hPa}$ are given in Table 3. Overall, the specific bulk density $\rho$ (calculated as the inverse of the specific bulk volume) of leek samples was smaller compared with both petunia and unplanted samples at $\mathrm{SL}, \mathrm{AE}$ and at $-10 \mathrm{hPa}$. The percentage of variability explained by the two first

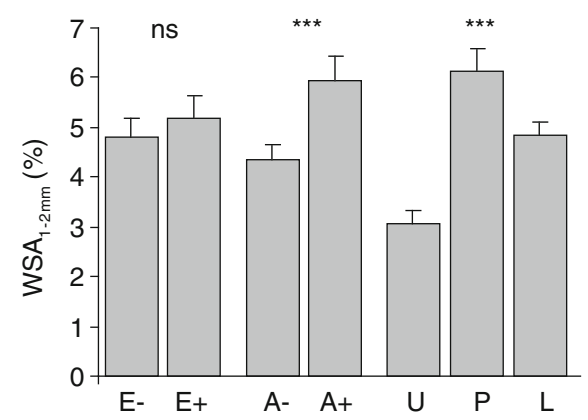

Fig. 3 Main effects of the presence of earthworms ( $E$, Allolobophora chlorotica), AMF (A, Glomus intraradices) and plant species (unplanted; petunia, Petunia hybrida; leek, Allium porrum) on the percentage of water-stable macroaggregates in the 1-2-mm size class $\left(\mathrm{WSA}_{1-2} \mathrm{~mm}\right)$. Bar represents mean $+\mathrm{SE}$ axes of the PCA was $88.27 \%$. The bulk densities $(\rho)$ at $\mathrm{SL}, \mathrm{AE}$ and at $-10 \mathrm{hPa}$ were significantly positively correlated with the first axis of the PCA $(P<0.001)$, while the specific structural porosities at SL and $\mathrm{AE}$, and the air-filled porosity at $-10 \mathrm{hPa}\left(A_{\text {sat }}\right)$ were significantly negatively correlated with the first axis of the PCA $(P<0.001)$. The specific plasma porosity at $\mathrm{SL}$, and the plasma water content at SL and AE were significantly positively correlated with the second axis $(P<0.001)$. Consequently, the results of the ANOVA performed on the coordinates of the axes showed that the first axis [i.e. positively correlated with the bulk density $(\rho)$ and negatively with the specific structural porosities] was marginally affected by plant species $\left(F_{2,20}=2.80, P=0.08\right)$. The coordinates of leek samples were smaller than the petunia samples and unplanted microcosms, which correspond to a smaller specific bulk density (i.e. greater specific bulk volume), and a larger specific structural porosity. For example, the specific bulk volume at saturation $V_{\text {sat }}$ was on average 0.84 $\pm 0.02 \mathrm{~cm}^{3} \mathrm{~g}^{-1}$ for the leek, $0.78 \pm 0.01 \mathrm{~cm}^{3} \mathrm{~g}^{-1}$ for the petunia and $0.77 \pm 0.02 \mathrm{~cm}^{3} \mathrm{~g}^{-1}$ for the unplanted 
Fig. 4 Examples of experimental shrinkage curves obtained in the different soil samples: (a) S-shape curve, (b) S-shape curve with interpedal phase as described by Braudeau et al. (2004), (c) double S-shape curve and (d) nonautoclaved soil
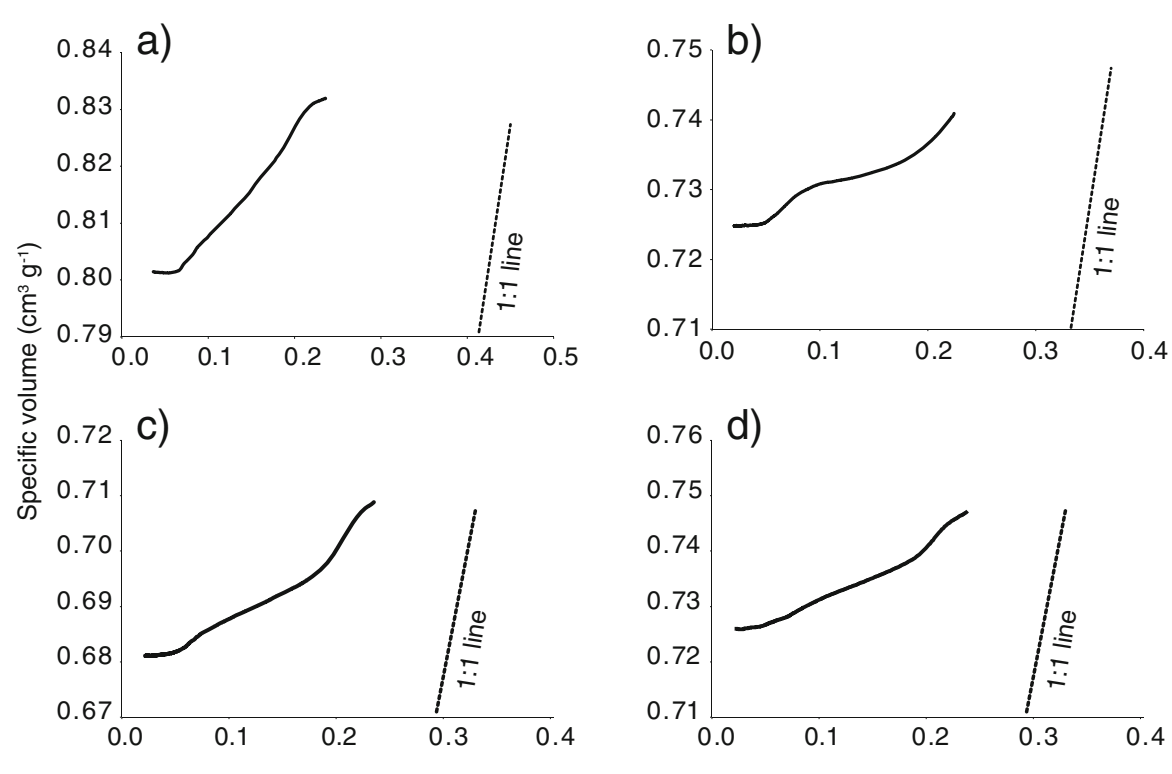

Gravimetric water content $\left(\mathrm{g} \mathrm{g}^{-1}\right)$

microcosms, respectively. Interestingly, the specific airfilled porosity at saturation $\left(A_{\text {sat }}\right)$ was marginally smaller with earthworms, but marginally larger in the presence of leek $\left(0.22 \pm 0.02 \mathrm{~cm}^{3} \mathrm{~g}^{-1}\right)$ compared with petunia $(0.18 \pm$ $\left.0.01 \mathrm{~cm}^{3} \mathrm{~g}^{-1}\right)$ and the control $\left(0.17 \pm 0.02 \mathrm{~cm}^{3} \mathrm{~g}^{-1}\right)$. The increase of $0.04 \mathrm{~cm}^{3} \mathrm{~g}^{-1}$ of $A_{\text {sat }}$ observed with leek compared with petunia is not accounting for all the increase in $V_{\text {sat }}\left(0.06 \mathrm{~cm}^{3} \mathrm{~g}^{-1}\right)$, which means that the volume of structural pores smaller than $150 \mu \mathrm{m}$ radius generated in the presence of leek was larger compared with petunia. The plasma pore volumes are similar to those found by Milleret et al. (2009b), but the soil specific volumes are smaller, thus denoting a smaller structural pore volume with this soil.

The drained pore size radii as estimated from tensiometer readings ranged from 2.2 to $125.7 \mu \mathrm{m}$. Figure 6 presents the cumulative volume of the drained pores as a function of their size for the different treatments. The observed effect of the treatments on the drained pores is in agreement with the effect observed on the air volume at $-10 \mathrm{hPa}$. The control shows a small pore volume (Fig. 6a) as expected with this poorly structured soil. The earthworms, however, slightly decrease the drained pore volumes (Fig. 6a). The plant roots tended to increase the pore volume, particularly in the case of leek, though this volume was largely varying within the samples (Fig. 6b-e). The volume increase is more pronounced with AMF (Fig. 6d) and partly limited in the presence of earthworms (Fig. 6c, e). Moreover, the total cumulative drained pore volume was significantly increased in the presence of AMF $\left(F_{1,20}=9.06, P=0.01\right)$. It was larger in the presence of AMF $\left(0.09 \pm 0.02 \mathrm{~cm}^{3} \mathrm{~g}^{-1}\right)$ than in the absence of AMF $\left(0.06 \pm 0.01 \mathrm{~cm}^{3} \mathrm{~g}^{-1}\right)$. Finally, compared with the air-filled pore volumes, the specific volumes occupied by the roots (Table 2) were about two to three orders of magnitude smaller.

\section{Discussion}

Effects of AMF and earthworms on plant growth

Despite a low mycorrhization rate, the presence of AMF significantly increased the shoot and root biomass for both plant species. This brings additional results to those of Milleret et al. (2009a) who only measured such an effect on leek plants and who attributed this increased growth to an increased $\mathrm{P}$ nutrient uptake by the leek roots in the presence of AMF. Although Scheu (2003) stated that earthworms positively affect plant growth, no effect on plant biomass was observed in the present experiment. Contrasting results, however, are reported in the literature about the effects of earthworms on plant growth, especially when earthworms are mixed with AMF (Eisenhauer et al. 2009; Li et al. 2012; Wurst et al. 2004; Wurst and Rillig 2011; Yu et al. 2005; Zaller et al. 2011). In the present study, only few earthworms were retrieved at the end of the experiment, which can explain this lack 
Fig. 5 Experimental shrinkage curves of all treatments. Unplanted treatments with earthworm ( $E$, grey dotted lines) in comparison with the unplanted control $(C$, grey lines) are represented in (a), the plant treatments: leek $(L)$ and petunia $(P)$ in (b), the plant + earthworms treatments $(L+E$ and $P+E)$ in (c), the plant $+\mathrm{AMF}(A)$ treatments $(L+A$ and $P+A)$ in (d) and the plant + earthworms $+\mathrm{AMF}(L+E+A$ and $P+E+A)$ in (e). For a better understanding of the figure, leek plant treatments, independently of the presence of earthworms and/or AMF, are represented with black lines and petunia plant treatments with black dotted lines. In order to compare the effects of plant species with unplanted microcosms, the control $(C)$ is shown everywhere $(\mathbf{b}-\mathbf{e})$
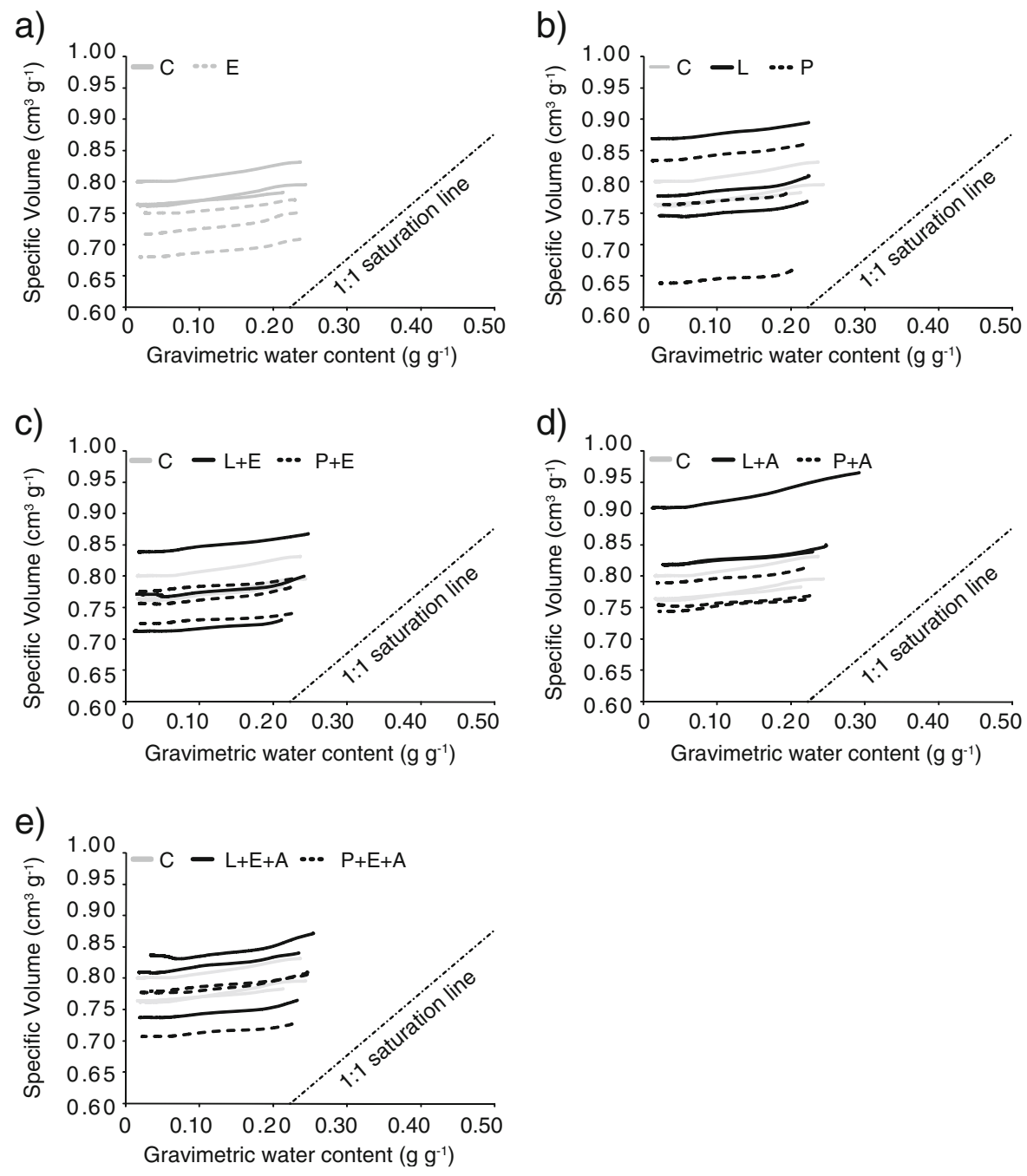

of effect on plant biomass. However, as earthworms decompose quickly into the soil, it was impossible to know how long they lived. Their potential effects on soil porosity or on plant growth could have been lessened over the experiment. Moreover, by comparing different sterilization techniques, Endlweber and Scheu (2006) highlighted that nitrogen availability was increased with autoclaving, which may have masked the earthworm effect. Therefore, the lack of significant earthworm effects has to be interpreted cautiously.

Despite no interactive effects between earthworm and AMF, both organisms had opposite effects on plant root architecture. While AMF increased the specific root length of plants, earthworms decreased their specific root volume. This effect may be attributed to the root abrasion or the ingestion of living plant parts by earthworms during bioturbation as reviewed in Brown et al. (2004).

\section{Experimental shrinkage curves}

To our best knowledge, shrinkage analyses were reported for soils such as oxisols, fluvisols, cambisols or vertisols, but not for silt loam Luvisol. The observed shrinkage curves show multiple linear and curvilinear parts, which raises questions about the structural behaviour of the soil and limits the application of XP model. This was not attributed to structural artefacts induced by autoclaving since the original undisturbed soils and repacked controls without autoclaving showed similar complex ShC patterns (Fig. 4d). The classical S-shape of ShC as proposed by XP model is based on the assumption of a bimodal 
pore size distribution (Braudeau 1988) that is to soils having well-differentiated plasma and structural pore systems (Boivin et al. 2004). The plasma pores are due to the colloidal constituents (clay minerals, oxides and organic matter). We were thus expecting that a weakly structured loamy soil would show less differentiated pore systems with poor distinction between plasma and structural. Accordingly, the plasma pore volumes at $\mathrm{SL}$ are very large considering the small clay content of this soil compared to previously reported results (e.g. Boivin et al. 2004), suggesting that silt size and rigid particles contribute to this pore system (Tessier 1980). The observed curve shapes may be an artefact due to anisotropic volume changes. Boivin (2007) showed that cracks opening or closing as well as a one-dimensional (1-D) vertical collapse may affect the conversion of 1-D height change to volume change (see Eq. 3). However, preliminary 3-D measurements on this soil showed a geometric factor close to 3 , meaning isotropic shrinkage, and no large cracks have been observed. Moreover, according to Braudeau et al. (1999) and Braudeau et al. (2004), interpedal swelling may have occurred, as suggested in Fig. 4b. However, this phenomenon was reported for ferralitic and Vertisols, with a slope of the interpedal phase close to 1 near water saturation. In our experiment, the slope of this part of the curve was much smaller than 1 (Fig. 5) and occurred in a range of suction values much smaller than $-10 \mathrm{hPa}$ (not presented); we cannot, therefore, conclude to interpedal swelling behaviour. Further studies focusing on the structural behaviour of the weakly aggregated loamy soils upon shrinkage are required for full interpretation of these curves. Though the soil physical characterization is, therefore, less comprehensive than expected, the corresponding information obtained in a single experiment is, however, much more comprehensive than provided by any alternative characterization method. Overall, the shrinkage analysis depicts a small porosity and structural stability of the Luvisol. Moreover, the structural stability is particularly small close to water saturation, which is in good agreement with field observations of silt-loam soils behaviour.

Effects of plant roots, AMF and earthworms on soil physical properties

Our study shows that the root systems of leek and petunia differently affected the soil physical 
Fig. 6 Cumulative drained pore volume vs. equivalent pore diameter. Unplanted treatments with earthworm ( $E$, grey dotted lines) in comparison with the unplanted control $(C$, grey lines) are represented in (a), the plant treatments: leek $(L)$ and petunia $(P)$ in $(\mathbf{b})$, the plant+earthworms treatments $(L+E$ and $P+E)$ in (c), the plant $+\mathrm{AMF}(A)$ treatments $(L+A$ and $P+A)$ in (d) and the plant +earthworms $+\mathrm{AMF}(L+E+A$ and $P+E+A)$ in (e). For a better understanding of the figure, leek plant treatments, independently of the presence of earthworms and/or AMF, are represented with black lines and petunia plant treatments with black dotted lines. The control $(C)$ is shown everywhere $(\mathbf{b}-\mathbf{e})$ in order to compare the effects of plant species with unplanted microcosms
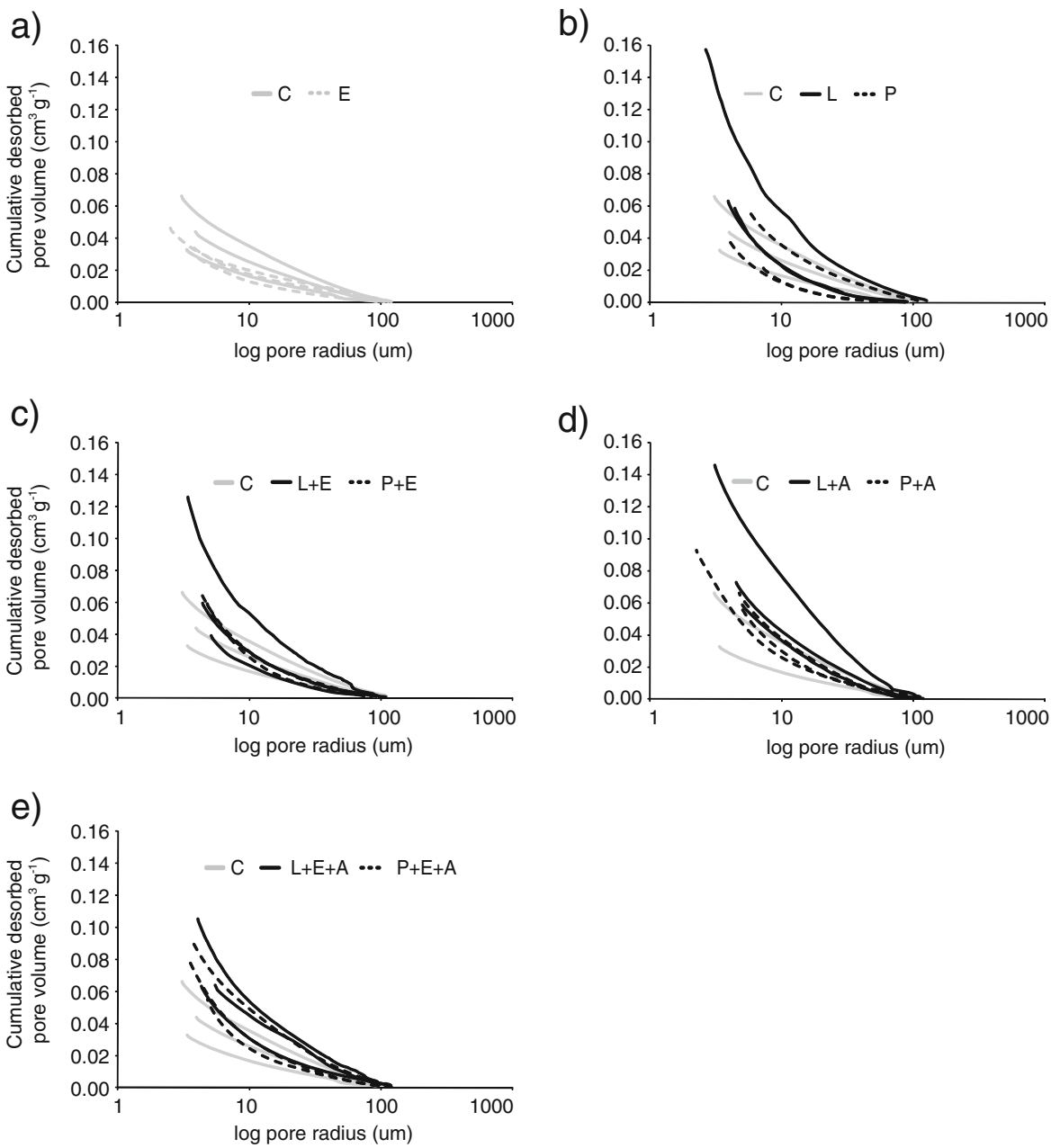

properties. The presence of leek in the microcosms marginally increased the specific bulk soil volume (i.e. decreased the bulk soil density) compared with the petunia, though a large variability among replicates of a single treatment was observed. Accordingly, total cumulative drained pore volume and the air-filled porosity at saturation (representing the pore radii greater than $150 \mu \mathrm{m}$ ) were larger in the presence of leek compared with petunia or the unplanted microcosms. The pore volume generated by both plant species was several orders of magnitude larger than the volume occupied by the roots themselves. Moreover, most root diameters were larger than $150 \mu \mathrm{m}$, which corresponds to air-filled porosity at $-10 \mathrm{hPa}$. It is thus likely that the drilling effect of roots is not the mechanism directly at the origin of the increase of porosity observed.

By measuring the percentage of stable macroaggregates $\left(\mathrm{WSA}_{1-2} \mathrm{~mm}\right.$ ), we found increased soil stability when plant roots were present in the microcosms compared with the unplanted microcosms. These results are in accordance with previous studies, showing a better soil structural stability in the presence of plant roots (e.g. Hallett et al. 2009; Milleret et al. 2009a), although in the present study, the response of the unstable loamy soil is unsurprisingly small compared to more structured soils. Furthermore, the aggregate stability of the soil was greater with petunia compared with leek roots. Miller and Jastrow (1990), Carter et al. (1994) and Haynes and Beare (1997) suggest that root morphology is important and determine the role of root penetration and its influence on soil aggregation. For example, Rillig et al. (2002) demonstrated that $\mathrm{WSA}_{1-2} \mathrm{~mm}$ was different according to plant species from similar grassland but differing in their functional role (forbs, grasses and legumes). The petunia root system was thinner, more branched and homogeneously distributed than the leek root network 
(visual observation). This is supported by the results of the root biomass and root length of both species. We therefore assume that leek root architecture (larger mean root diameter, less branched) mostly increased the specific bulk soil volume and porosity, while the petunia root network (larger volume of small diameter roots) mostly increased the soil stability with a better physical root enmeshment of the soil or by releasing binding organic material within the rhizosphere (Six et al. 2004). Our results point out how the root architecture of monocotyledon and dicotyledon plants may differently engineer the soil structure.

On the whole, the presence of AMF increased the percentage of water-stable macroaggregates $\left(\mathrm{WSA}_{1-2} \mathrm{~mm}\right.$ ) as previously described by several authors (Jastrow et al. 1998; Rillig et al. 2002; Rillig and Mummey 2006). In parallel, the samples containing plants and AMF showed a larger specific soil volume when AMF was grown with leek than with petunia. This trend was also observed in the pore volume graph (Fig. 6). The percentage of root mycorrhization was small in the present experiment. It seems consequently that the presence of plants rather than the presence of AMF had the largest impact on increasing soil stability, as previously described by Hallett et al. (2009).

Overall, our results are in good agreement with the findings of e.g. Hallett et al. (2009), Feeney et al. (2006) and Crawford et al. (2012). In this study, the effects of roots, fungi and bacteria were combined. Accordingly to the previous studies, we found an increase in pore volume and soil structural stability, with roots showing the larger effects. The observed effects were smaller with the Luvisol than with the Anthrosol, which can be attributed to the difference in size and nature of the soil minerals, resulting in a lower response to self-organization (Crawford et al. 2012). Additionally, we showed that (1) the two root systems have a different impact on the soil bulk volume and porosity for leek and on soil stability for petunia, (2) only the structural pores are affected by the soil biota and (3) the generated pore volumes and corresponding pore diameters are much larger than the respective volumes and diameters of the root systems. Combined effect of roots and stimulated bacteria and fungi could explain this increase of soil porosity, with root growth moving soil particles and microbial activity stabilizing the created porosity as assumed by Milleret et al. (2009b). The corresponding changes are beneficial to both plant and microorganisms. This strongly supports the idea of a self-organization of the soil-(plant)-microorganism complex (Young and Crawford 2004).

At any water content, the presence of earthworm without plants decreased the specific bulk volume of the soil (i.e. increased the soil density). Though the earthworm weight was small at the end of this experiment, this result is in agreement with the reports of Chauvel et al. (1999) for tropical earthworms in the field, and Milleret et al. (2009b) with the same earthworm species as in the present study but using a soil showing a more developed structural porosity and tenfold more stable structure. These changes went with a decrease of the pore volume at any pore size. At saturation, the specific bulk soil density was $1.35 \mathrm{~g}$ $\mathrm{cm}^{-3}$ in the presence of earthworms and corresponded to initial bulk density measured in the field (Chenu, personal communication). The compaction effect of earthworms was, however, limited when plants were present in the microcosm. In such cases, plant roots decreased the specific bulk soil density. Note that contrarily to plant and fungi, the earthworm activity alone did not lead, in this experiment, to improved soil properties. In other words, endogeic earthworms alone did not contribute to self-organization.

The observed physical effects of soil biota are not only influenced by plant species, but also much smaller in intensity than with the Anthrosol. The smaller changes in structural stability and porosity observed with the loamy unstable soil compared to the previously experimented highly structured Anthrosol were not expected considering that the loamy soil showed a fair response to structure improvement practices (Chenu et al. 2011; Cosentino et al. 2006), but it is in agreement with the common observation of weak structuration of this soil.

\section{Conclusions}

This work confirmed the increase of plant production in the presence of AMF, while no direct effect of earthworms nor interaction of earthworm with AMF were observed. Despite partly applied only, due to non-conventional ShC shapes, shrinkage analyses allowed quantifying the changes induced by the soil biota on the soil physical properties at clod scale. Especially, the present study highlighted a compacting 
effect of $A$. chlorotica on a silt-loam soil. In addition, the root system of both plant species increased soil porosity and the changes exceeded by far their foraging volume, thus suggesting another structural effect than direct drilling. Moreover, we showed that two different root systems induced different impacts on the soil structure, which can be attributed to the structure of the root system. The unstable loamy soil showed limited physical response to the soil biota compared to previous experimented soils, either upon structure improvement or degradation factors. According to these observations, the ameliorating effect of biota on soil structure is highly dependent on the initial level of porosity and aggregate stability, and/or nature of the soil colloidal constituents. Indeed, this effect cannot be viewed as a simple additive effect, which may be of consequence in designing ecological strategies to remediate structurally degraded soils. In such case, the impact of selected "ameliorating" biota on soil structure for a range of initial states should be determined.

Acknowledgments This project was funded by the National Centre of Competence in Research (NCCR) Plant Survival, a research programme of the Swiss National Science Foundation. The authors are very grateful to Lidia Mathys-Paganuzzi and Marie-Laure Heusler for their excellent technical assistance in the laboratory, to Frederic for supervision of the experimental setup and to François Fullemann for technical assistance during the greenhouse experiment. We are also very grateful to the person responsible for the INRA long-term experiment of La Cage at Versailles, for allowing us to sample the soil, and to Prof. Didier Reinhardt for the Petunia seeds. We finally thank the two anonymous reviewers for their comments and suggestions.

\section{References}

Amezketa E (1999) Soil aggregate stability: a review. J Sustain Agric 14(2-3):83-151

Angers DA, Caron J (1998) Plant-induced changes in soil structure: processes and feedbacks. Biogeochemistry 42(12):55-72

Angle JS, McGrath SP, Chaney RL (1991) New culture-medium containing ionic concentrations of nutrients similar to concentrations found in the soil solution. Appl Environ Microbiol 57(12):3674-3676

Boivin P (2007) Anisotropy, cracking, and shrinkage of vertisol samples-experimental study and shrinkage modeling. Geoderma 138(1-2):25-38

Boivin P, Brunet D, Gascuel-Odoux C (1990) Une nouvelle méthode de mesure de la densité apparente sur échantillons de sols non remaniés. Bull Group Fr Humidimétrie Neutron Tech Assoc 28:57-71

Boivin P, Garnier P, Tessier D (2004) Relationship between clay content, clay type, and shrinkage properties of soil samples. Soil Sci Soc Am J 68(4):1145-1153

Boivin P, Schaeffer B, Temgoua E, Gratier M, Steinman G (2006) Assessment of soil compaction using shrinkage curve measurement and modeling. Experimental results and perspectives. Soil Tillage Res 88:65-79

Bradford MA, Jones TH, Bardgett RD, Black HIJ, Boag B, Bonkowski M, Cook R, Eggers T, Gange AC, Grayston SJ, Kandeler E, McCaig AE, Newington JE, Prosser JI, Setala H, Staddon PL, Tordoff GM, Tscherko D, Lawton JH (2002) Impacts of soil faunal community composition on model grassland ecosystems. Science 298(5593):615-618

Braudeau E (1988) General shrinkage curve equation for undisturbed soil samples. C R Acad Sci II 307(15):1731-1734

Braudeau E, Bruand A (1993) Détermination de la courbe de retrait de la phase argileuse à partir de la courbe de retrait sur échantillon de sol non remanié. Application à une séquence de sols de Côte-d'Ivoire. C R Acad Sci II 316(5):685-692

Braudeau E, Costantini JM, Bellier G, Colleuille H (1999) New device and method for soil shrinkage curve measurement and characterization. Soil Sci Soc Am J 63(3):525-535

Braudeau E, Frangi JP, Mohtar RH (2004) Characterizing nonrigid aggregated soil-water medium using its shrinkage curve. Soil Sci Soc Am J 68(2):359-370

Brewer R (1964) Fabric and mineral analysis of soils. Wiley, New York

Brown GG, Edwards CA, Brussaard L (2004) How earthworms affect plant growth: burrowing into the mechanisms. In: Edwards CA (ed) Earthworm ecology. CRC, Boca Raton, pp 13-49

Carter MR, Angers DA, Kunelius HT (1994) Soil structural form and stability, and organic-matter under cool-season perennial grasses. Soil Sci Soc Am J 568:1194-1199

Chauvel A, Grimaldi M, Barros E, Blanchart E, Desjardins T, Sarrazin M, Lavelle P (1999) Pasture damage by an Amazonian earthworm. Nature 398:32-33

Chen DH, Saleem Z (1986) A new simplex procedure for function minimization. Int J Model Simul 6(3):81-85

Chenu C, Abiven S, Annabi M et al (2011) Mise au point d'outils de prévision de l'évolution de la stabilité de la structure de sols sous l'effet de la gestion organique des sols. Etude Gestion Sols 18(3):161-174

Cosentino D, Chenu C, Le Bissonnais Y (2006) Aggregate stability and microbial community dynamics under drying-wetting cycles in a silt loam soil. Soil Biol Biochem 38:2053-2062

Crawford JW, Deacon L, Grinev D, Harris JA, Ritz K, Singh BK, Young I (2012) Microbial diversity affects selforganization of the soil-microbe system with consequences for function. J R Soc Interface 9:1302-1310

Edwards CA, Bohlen PJ (1996) Biology and ecology of earthworms, 3rd edn. Chapman \& Hall, London

Eisenhauer N, König S, Sabais ACW, Renker C, Buscot F, Scheu S (2009) Impacts of earthworms and arbuscular mycorrhizal fungi (Glomus intraradices) on plant performance are not interrelated. Soil Biol Biochem. doi:10.1016/j.soilbio.2008.12.017 
Endlweber K, Scheu S (2006) Establishing arbuscular mycorrhiza-free soil: a comparison of six methods and their effects on nutrient mobilization. Appl Soil Ecol 34:276-279

Feeney DS, Crawford JW, Daniell T, Hallett PD, Nunan N, Ritz K, Rivers M, Young IM (2006) Three-dimensional microorganization of the soil-root-microbe system. Microb Ecol 52(1):151-158

Haines WB (1923) The volume-changes associated with variations of water content in soil. J Agric Sci 13:296-310

Hallett P, Feeney D, Bengough A, Rillig M, Scrimgeour C, Young I (2009) Disentangling the impact of AM fungi versus roots on soil structure and water transport. Plant Soil 314(1-2):183-196

Haynes RJ, Beare MH (1997) Influence of six crop species on aggregate stability and some labile organic matter fractions. Soil Biol Biochem 29(11-12):1647-1653

Jastrow JD, Miller RM (1991) Methods for assessing the effects of biota on soil structure. Agric Ecosyst Environ 34(14):279-303

Jastrow JD, Miller RM, Lussenhop J (1998) Contributions of interacting biological mechanisms to soil aggregate stabilization in restored prairie. Soil Biol Biochem 30(7):905916

Kemper WD, Rosenau RC (1986) Aggregate stability and size distribution. In: Klute A (ed) Methods of soil analysis, Part 1. Physical and mineralogical methods, Vol. 1, vol 5, 2nd edn, Soil Science Society of America Book Series. Soil Science Society of America, Madison, pp 425-442

Koide RT, Li MG (1989) Appropriate controls for vesicular arbuscular mycorrhiza research. New Phytol 111(1):35-44

Lawrence GP (1977) Measurement of pore sizes in fine-textured soils - review of existing techniques. J Soil Sci 28(4):527540

Le S, Josse J, Husson F (2008) FactoMineR: an R package for multivariate analysis. J Stat Softw 25:1-18

Li H, Li X, Dou Z, Zhang J (2012) Earthworm (Aporrectodea trapezoides)-mycorrhiza (Glomuns intraradices) interaction and nitrogen and phosphorus uptake by maize. Biol Fertil Soils 48:75-85

McGonigle TP, Miller MH, Evans DG, Fairchild GL, Swan JA (1990) A new method which gives an objective-measure of colonization of roots by vesicular arbuscular mycorrhizal fungi. New Phytol 115(3):495-501

Miller RM, Jastrow JD (1990) Hierarchy of root and mycorrhizal fungal interactions with soil aggregation. Soil Biol Biochem 22(5):579-584

Milleret R, Le Bayon RC, Gobat JM (2009a) Root, mycorrhiza and earthworm interactions: their effects on soil structuring processes, plant and soil nutrient concentration and plant biomass. Plant Soil 316(1-2):1-12. doi:10.1007/s11104008-9753-7

Milleret R, Le Bayon RC, Lamy F, Gobat JM, Boivin P (2009b) Impact of roots, mycorrhizas and earthworms on soil physical properties as assessed by shrinkage analysis. J Hydrol 373(3-4):499-507. doi:10.1016/j.jhydrol.2009.05.013
Pelosi C, Bertrand M, Roger-Estrade J (2009) Earthworm community in conventional, organic and direct seeding with living mulch cropping systems. Agron Sustain Dev 29:287-295

R Development Core Team (2007) R: a language and environment for statistical computing. R Foundation for Statistical Computing, Vienna, Austria. http://www.R-project.org

Rillig MC, Mummey DL (2006) Mycorrhizas and soil structure. New Phytol 171(1):41-53

Rillig MC, Wright SF, Eviner VT (2002) The role of arbuscular mycorrhizal fungi and glomalin in soil aggregation: comparing effects of five plant species. Plant Soil 238(2):325333

Schaeffer B, Schulin R, Boivin P (2008) Changes in shrinkage of restored soil caused by compaction beneath heavy agricultural machinery. Eur J Soil Sci 59(4):771-783

Scheu S (2003) Effects of earthworms on plant growth: patterns and perspectives. Pedobiologia 47(5-6):846-856

Six J, Bossuyt H, Degryze S, Denef K (2004) A history of research on the link between (micro)aggregates, soil biota, and soil organic matter dynamics. Soil Tillage Res 79(1):731

Tessier D (1980) Sur la signification de la limite de retrait des argiles. CR Acad Sci Paris 291D:377-380, In French

Thomas RS, Franson RL, Bethlenfalvay GJ (1993) Separation of vesicular-arbuscular mycorrhizal fungus and root effects on soil aggregation. Soil Sci Soc Am J 57(1):77-81

Tisdall JM, Oades JM (1982) Organic-matter and water-stable aggregates in soils. J Soil Sci 33(2):141-163

Wardle DA, Bardgett RD, Klironomos JN, Setala H, van der Putten WH, Wall DH (2004) Ecological linkages between aboveground and belowground biota. Science 304(5677):1629-1633

Wurst S, Rillig MC (2011) Additive effects of functionally dissimilar above- and belowground organisms on a grassland plant community. J Plant Ecol 4(4):221-227

Wurst S, Dugassa-Gobena D, Langel R, Bonkowski M, Scheu S (2004) Combined effects of earthworms and vesiculararbuscular mycorrhizas on plant and aphid performance. New Phytol 163(1):169-176

Wurst S, Allema B, Duyts H, van der Putten WH (2008) Earthworms counterbalance the negative effect of microorganisms on plant diversity and enhance the tolerance of grasses to nematodes. Oikos 117(5):711-718. doi:10.1111/ j.2008.0030-1299.16333.x

Young IM, Crawford JW (2004) Interactions and selforganization in the soil-microbe complex. Science 304(5677):1634-1637

Yu XZ, Cheng JM, Wong MH (2005) Earthworm-mycorrhiza interaction on Cd uptake and growth of ryegrass. Soil Biol Biochem 37(2):195-201

Zaller JG, Heigl F, Grabmaier A, Lichtenegger C, Piller K, Allabashi R, Frank T, Drapela T (2011) Earthwormmycorrhiza interactions can affect the diversity, structure and functioning of establishing model Grassland communities. PLoS One 6(12):e29293 